683

\section{FLACCID PARAPARESIS FOLLOWING PNEUMOCOCCAL MENINGITIS: A CASE REPORT AND REVIEW OF LITERATURE}

\author{
V. Palanivel ${ }^{1}$, M.A. Anjay ${ }^{2}$, P. Prabhakar ${ }^{1}$ \\ ${ }^{1}$ Department of Neurosciences, ${ }^{2}$ Department of \\ Respiratory Paediatrics, Great Ormond Street \\ Hospital for Children, London, UK
}

Background \& Aims: To describe an unusual case of acute flaccid paralysis following pneumococcal meningitis and to review the relevant literature.

Methods: Case report and literature review

Results: A 13.5 year old was admitted to the paediatric intensive care unit with pneumococcal meningitis and multi-organ dysfunction. A few days into the illness she developed flaccid weakness of lower limbs with diminished reflexes. She also developed facial weakness and bulbar dysfunction. There was bladder and bowel incontinence. Magnetic Resonance Imaging of brain and spine as well as nerve conduction studies were normal. Cerebrospinal fluid analysis revealed raised protein with albuminocytologic dissociation. She was suspected to have an acute inflammatory demyelinating polyneuropathy or post infectious myelitis triggered by pneumococcus. She was treated with intravenous steroids and made a gradual recovery, but still had residual neurologic sequelae at the time of discharge.A review of literature showed that acute spinal cord dysfunction following pneumococcal meningitis is extremely rare even in adults and has never been reported in children.

Conclusions: Pneumococcal meningitis can be rarely complicated by spinal cord dysfunction.

\section{4}

\section{THE EVALUATION OF PARENT SATISFACTION IN PEDIATRIC CARDIOVASCULAR SURGERY INTENSIVE CARE UNIT}

\author{
G. Gok ${ }^{1}$, S. Kuguoglu ${ }^{2}$
}

\begin{abstract}
${ }^{1}$ Melek Hatun Maternal and Child Health Center, ${ }^{2}$ Pediatric Nursing, Acibadem University, Health Science Faculty Division of Nursing, Part Time Faculty, Istanbul, Turkey
\end{abstract}

Aims: This study is planned to measure the satisfaction of families whose children are cared in pediatric cardiovascular surgery critical intensive care unit (PCVSICU).

A descriptive and cross sectional design was used to explore the use of parent satisfactions.

Methods: Research population is determined as parents whose children are cared inhospitals

located in Istanbul and cared in a PCVSICU after cardiovascular surgery. The sample includes the parents $(n=452)$ whose children are treated in PCVSICU. Parent Satisfaction in Pediatric Intensive Care Unit Survey and the socio-demographic survey are carried out to parents simultaneously.

Results: In study, means and standard deviations of parent satisfaction are \%77.00 $\mp 8.20, \% 76.08$ $\mp 6.60$, and $\% 79.30 \mp 6.40$ for two state hospitals and a foundation hospital, respectively. Moreover, we compare PCVSICU environment satisfaction, care satisfaction and communication satisfaction with overall parent satisfaction two by two, there is a significant positive correlation between the factors and overall satisfaction. Moreover, when the parents are grouped with respect to regions of Turkey, parents from Aegean region of Turkey are significantly less satisfied with hospital care when compared to the rest of regions $(p<0.05)$. In a same manner, we create various groups from parents with respect to their sex, age, education levels, and income levels to compare the group satisfaction each other, however, none of the groups differs significantly from each other $(p>0.05)$.

Conclusions: We conclude that the time spent by patients in PICU does not influence the satisfaction level of their parents $(p>0.05)$.

\section{5}

\section{POSTTRAUMATIC STRESS DISORDER IN THE NEONATAL INTENSIVE CARE UNIT}

\section{Ribeiro}

Neonatal Intensive Care, University of California, Los Angeles, Santa Monica, CA, USA

There is evidence to suggest that having one's baby in the neonatal intensive care unit (NICU) may cause post traumatic stress disorder (PTSD). PTSD is defined in the Diagnostic Statistical Manual IV (DSM IV) as state in which having been exposed to a traumatic event, the victim persistently re-experiences the traumatic event (intrusive recollections, dreams, intense psychological/ 
physiological distress to cues that symbolize event). As a result the victim avoids the stimuli associated with trauma and has increased arousal (ex. hyper vigilance, exaggerated startle, insomnia, outburst of anger). The disturbance needs to last greater than 1 month and cause significant distress and/ or impairment in social, occupational, or other important areas of functioning. A hospitalization, especially an unexpected hospitalization can be seen as a traumatic event due to threat of death, disability, disfigurement. There are several potential consequences to parental PTSD including marital discord and behavioral problems in children (Peebles-Kleiger, 2000). It is important to explore methods of mitigating parental stress. It is also important to recognize that fathers and marginalized populations may cope differently. It was found that the highest distress was seen in the lowest educational level, (Holditch-Davis, et al., 2009). Staff is also vulnerable to PTSD due to prolonged exposure to grotesque sights, length of time in crisis and emotional identification with patients (similar in age, gender, temperament with one's own child). In summary, PTSD does occur in the NICU environment and may have long term negative consequences.

\section{6}

\section{PASSIVE SMOKING IN CHILDREN AT HIGH SOCIO-CULTURAL AND ECONOMIC LEVEL AND PARENTS' OPINIONS ABOUT THE EFFECTS OF PASSIVE SMOKING}

\author{
N. Cinar ${ }^{1}$, R. Cevahir ${ }^{1}$, C. Dede ${ }^{2}$, S. Kuguoglu ${ }^{3}$ \\ ${ }^{1}$ Sakarya University, School of Health Sciences, \\ 2Sakarya University, Vocational School of Health \\ Sciences, Sakarya, ${ }^{3}$ Acibadem University, Health \\ Science Faculty Division of Nursing, Part Time \\ Faculty, Istanbul, Turkey
}

Objective: This study was conducted to determine exposure to tobacco smoke at home in children whose parents at high socio cultural and economic level and parents' opinions about the effects of passive smoking in children.

Method: The survey data was collected on a random sample of 290 parents of children who attended from two private schools in Sakarya (2007). All parents in the sample received an anonymous self-administered questionnaire containing an explanation about the purpose of the study, pointing out the participation is voluntary.
Results: $40.7 \%$ of fathers and $32.8 \%$ of mothers were university graduates. $46.6 \%$ of families have described to their economic situation as good. $54.5 \%$ of families were smokers, \% 20.3 of both mother and father were identified as smokers. $16.9 \%$ of the parents had reported their children exposed to cigarette smoke at home, $82.4 \%$ of families have an opinion that they have reported passive smoking of children may lead respiratory diseases, $72.4 \%$ the immune system weakens, $72.1 \%$ a desire to smoke in the future.

Conclusion: The majority of the parents are known to health effects of the passive smoking on the children. Despite this, nearly one in five is exposed to their children to tobacco smoke at home. By adapting to the parents to adverse effects of passive smoking for the health of children and particularly babies at individual and family health awareness programs, changes in behavior must be established.

\section{7}

\section{PHARMACOKINETIC STUDY (A2210378) COMPARING TWO PEDIATRIC PARACETAMOL SUSPENSIONS SHOWS BIOEQUIVALENCE, AND FASTER EARLY ABSORPTION OF NEW FORMULATION}

S. Smith ${ }^{1}$, B. Colgan ${ }^{1}$, D. McLaverty ${ }^{1}$, J. Stewart ${ }^{1}$, J. Hanna1', L. Heaslip ${ }^{1}$, Y. Yue ${ }^{2}$, A. Collaku², Y.-Y. Starkey ${ }^{2}$, N. Kronfeld ${ }^{2}$, G. Clarke ${ }^{2}$

${ }^{1}$ MDS Pharma Services INC, Belfast, UK, ${ }^{2} \mathrm{GSKCH}$, Parsippany, NJ, USA

Objective: To compare a new formulation, Paracetamol Pediatric Suspension (PPS), designed to reach therapeutic levels rapidly, to marketed

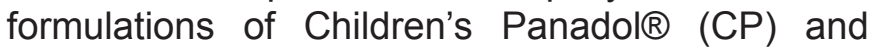
Panodil $\circledast$ Baby \& Infant Suspensions (PBIS). The trial measured the rate and extent of absorption and bioequivalence in fasted and semifed states of the three paracetamol formulations.

Methods: A pivotal, single-center, open-label, sixway crossover pharmacokinetic (PK) study, in 28 healthy, male, adult-volunteers. These subjects received a single oral dose of $1.0 \mathrm{~g}$ paracetamol in three randomized treatments in fasted and semifed states with a 24-hour washout period between doses during a 7-day/6-night residential period at the study site.

Results: Regression analyses of $A \cup C_{010 \mathrm{hrs}}, A \cup C_{0 \text {-inf' }}$, and $\mathrm{C}_{\max }$ confirmed that the three formulations were 